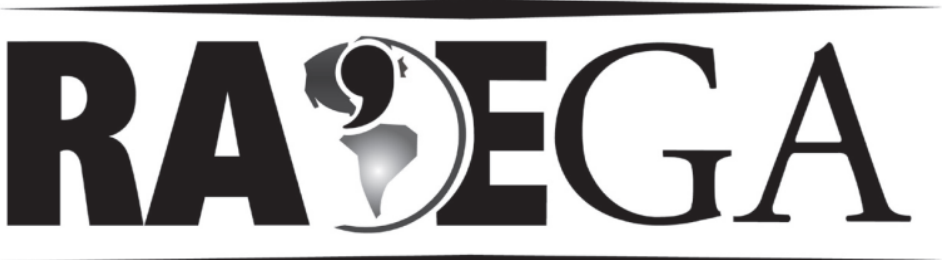

O ESPAÇO GEOGRÁFICO EM ANÁLISE

\title{
As experiências de regionalizações, políticas públicas e o papel do Estado brasileiro no século XXI
}

\author{
The experiences of regionalization, public policy and the \\ role of the Brazilian State in the XXI century
}

Karla Christina Batista de França ${ }^{1}$

\section{Resumo}

Este artigo analisa algumas expressões das diferentes perspectivas de regionalizações que marcaram o ordenamento territorial brasileiro ao longo dos séculos XX e XXI, em especial, as regionalizações oficiais do Instituto Brasileiro de Geografia e Estatística com alinhamentos teóricos da ciência geográfica. Não se trata de um estudo aprofundado dos desdobramentos epistemológicos da Geografia Regional. Antes, refere-se a uma reflexão acerca dos limites e avanços empreendidos diante dos diferentes critérios utilizados para a atuação eficiente das políticas públicas, analisando-se aqui os Eixos Nacionais de Integração e Desenvolvimento (ENIDs) e a Política Nacional de Desenvolvimento Regional (PNDR). Os pressupostos metodológicos foram estabelecidos com base em três movimentos: por meio da caracterização geral das políticas analisadas; das metodologias de regionalização das políticas, isto é, dos critérios para a ação de regionalizar; e das estratégias de ações das políticas.

Palavras-chave: regionalização; metodologia; geografia; ENIDs; PNDR.

\section{Abstract}

This article examines some expressions of the different perspectives of regionalization that marked the Brazilian land use along the $X X$ and $X X I$ centuries, in particular, regionalization official the IBGE

\footnotetext{
${ }^{1}$ Doutoranda em Geografia. Universidade de Brasília - UnB, Brasília-DF, Brasil. karlinha@unb.br
} 
theoretical alignments of geographical science. This is not an in-depth study of epistemological Regional Geography. Rather, it refers to a reflection on the limits and advances made on the different criteria used for the efficient operation of public policies - we have discussed Axis National Integration and Development and National Policy for Regional Development. The methodological assumptions were established from three movements, which are: a general characterization of the policies reviewed, the methods of regionalization policies and the criteria for action and regionalization, the strategies of political action.

key words: regionalization; methodology; geography; ENIDs ; PNDR.

\section{Introdução}

O presente artigo traz uma análise das diferentes perspectivas de regionalizações, no contexto nacional, ao longo do século $X X$ e $X X I$, as quais condicionaram o ordenamento territorial e contribuíram para o fomento de políticas públicas.

O texto é composto de três partes. Na primeira, apresentam-se apontamentos embasados nos conceitos de região e regionalização com alinhamentos da ciência geográfica que subsidiaram as divisões regionais do Brasil, sobretudo a partir das divisões regionais oficiais do Instituto Brasileiro de Geografia e Estatística. Na segunda parte analisam-se as políticas e/ou programas nacionais e suas estratégias de regionalização para o fomento ao desenvolvimento e a redução das desigualdades, como por exemplo, os Eixos Nacionais de Integração e Desenvolvimento e a Política Nacional de Desenvolvimento Regional. O objetivo é evidenciar as ações estratégicas levando em consideração os critérios ou aspectos técnicos e as regionalizações diferenciadas das respectivas políticas públicas. Na última parte, das considerações finais, apontam-se as limitações e os avanços que potencializaram as ações das políticas públicas a partir dos recortes regionais.

\section{Região e Regionalização: uma leitura geográfica²}

As matrizes teóricas da ciência geográfica contribuem para as análises do conceito de região, sobretudo na perspectiva dos avanços na consolidação

\footnotetext{
2 O debate das perspectivas teóricas do conceito de região foi baseado na dissertação da pesquisadora defendida no PPGEA-UnB no ano de 2009 e, no estudo dirigido na disciplina Tópicos Especiais em Geografia ofertada no 1/2012 pelo PPGEA-UnB
} 
do pensamento geográfico. Nesse sentido, opta-se, neste texto, por não se aprofundar nos constructos teóricos da discussão da região na ciência geográfica, e sim por analisar os aspectos importantes que marcaram algumas rupturas e continuidades na leitura da região, que dizem respeito às perspectivas e metodologias das regionalizações brasileiras.

É importante situar o leitor acerca dessas rupturas e continuidades da região, pelo fato de a historiografia das divisões regionais oficiais do IBGE levar em consideração os aspectos analíticos da conceituação de região, na trajetória das experiências de regionalização no Brasil, o que pode instigar análises historiográficas das regionalizações, correlacionando-as com a dimensão empírica. Os avanços, critérios e metodologias que marcaram a produção do espaço e as ações regionalizadoras no país somente serão compreendidos a partir do par teoria-empírico.

Portanto, ao abordar os momentos de rupturas e de continuidades da região na geografia, concorda-se com Haesbaert (2010), quando este afirma que o conceito de região não se resume à simplicidade de recortes empíricos categoria real ou a categoria analítica - a partir de elementos subjetivos do pesquisador. Antes, devem-se buscar as mediações entre o real e o analítico.

Nessa direção, torna-se premente ressaltar os percursos analíticos e condicionantes do conceito de região. As últimas décadas do século XIX foram marcadas profundamente pela institucionalização da Geografia como ciência, o que Correa (1987) atribuiu à simultaneidade destes dois movimentos: o do capital monopolista, que buscava novas áreas para sua expansão territorial; e o da ciência geográfica, que alcançava as instituições de ensino superior na Europa, com diferentes concepções epistemológicas, marcando a produção científica da geografia, inclusive concepções que vêm sendo resgatadas no período atual do século XXI.

Ao tratar das transformações da ciência geográfica, é comum a sua vinculação às escolas do pensamento geográfico, com destaque para a alemã e a francesa. Moreira (2008) ressalta que, na maioria das vezes, ocorre um reducionismo da produção do pensamento dos autores quando suas obras são vinculadas a uma escola geográfica e ao Estado. A título de exemplificação, 
citem-se o Estado alemão, e consequentemente o aporte dos pressupostos deterministas, ou o Estado francês, com os pressupostos possibilistas.

Essa vinculação das diversas matrizes do pensamento geográfico a uma escola generaliza e enviesa a relevância das obras condicionadas e utilizadas como justificativas para uma ação estatal, como ocorrem nas leituras equivocadas das obras de Paul Vidal de La Blache e Friedrich Ratzel. Para Moreira (2008), ambos os autores tinham como foco central a relação homemnatureza, mas com abordagens que se diferenciavam na questão da apropriação do homem-natureza.

Trata-se de transformações que também marcaram a institucionalização da geografia no Brasil, sobretudo com a vinda de geógrafos franceses, que fomentaram diversas linhas e métodos de pesquisas. Isso ocorreu, em especial, nos primeiros cursos universitários de geografia na Universidade de São Paulo, em 1934, e na Universidade do Brasil (atual UFRJ), em 1935, como também em institutos como o IBGE, em 1937, e no arcabouço teórico da Revista Brasileira de Geografia (RBG) no ano de 1939 e do Boletim Paulista de Geografia (Correa, 1987; Bezzi, 2004; Moreira, 2008).

Uma correlação das bases conceitual e metodológica permite compreender que as transformações da região são condicionadas pelos elementos teóricos da ciência geográfica e pelos processos espaciais. A partir da relação homem-natureza (aspectos naturais e "humanizados"), é possível observar como os aspectos teóricos e empíricos marcaram as produções geográficas alemãs e francesas e influenciaram as proposições das divisões regionais no Brasil. Desde a primeira regionalização oficial do Conselho Nacional de Geografia, em 1941, pode-se inferir que houve articulação dos elementos constituidores das regiões naturais das matrizes clássicas da geografia, dando relevância aos fatores físicos para a uniformidade de parcelas do espaço, como determinado tipo de clima, vegetação e formas de relevo.

A orientação metodológica pela predominância de aspectos naturais para delimitar a primeira regionalização brasileira foi baseada no grau de estabilidade dos elementos físicos. Na perspectiva de uniformidade dos elementos naturais, Correa (1987, p. 23-24) afirma que: 
[...] a região natural é entendida como uma parte da superfície da Terra, dimensionada segundo escalas territoriais diversificadas, e caracterizadas pela uniformidade resultante da combinação ou integração em área dos elementos da natureza: o clima, a vegetação, o relevo, a geologia e outros adicionais que diferenciariam ainda mais cada uma dessas partes.

Nesse sentido, a primeira regionalização oficial do Brasil (Fig. 1) ressaltava a estabilidade dos critérios naturais. Para Magnago (1995), os critérios naturais possibilitaram uma melhor aproximação de elementos e de dados para fins estatísticos, por um longo tempo, com base em uma regionalização que, em certa medida, não apresentava grandes alterações em seus limites.

No entanto, é preciso fazer algumas ponderações acerca dessa primeira regionalização oficial ${ }^{3}$. Cabe assinalar que anteriormente à sua instituição, nas propostas de regionalizações existentes, os objetivos eram diversos, com propostas tanto para finalidades didáticas quanto para o ordenamento territorial. No século XIX, especificamente em 1843, foram mapeadas as primeiras tentativas de regionalizações, como apresenta Bezzi (2004) (quadro $01)^{4}$.

\footnotetext{
${ }^{3}$ No documento Evolução da divisão territorial do Brasil 1872-2010, elaborado pelo IBGE (2011), foram analisadas as transformações territoriais brasileiras e a evolução do número de municípios desde o primeiro recenseamento realizado no Brasil no ano de 1872, que contribuíram para consolidar as diferentes regionalizações existentes antes da oficial.

${ }^{4} \mathrm{O}$ quadro sistematiza fragmentos da série histórica de regionalizações que, em certa medida, contribuíram para a primeira regionalização oficial do Brasil. Nesse sentido, cabe o registro de que não é objetivo deste estudo aprofundar-se nas regionalizações que precederam a oficial, mas tão somente reconhecer a importância delas para a elaboração da regionalização oficial.
} 
Quadro 01: Divisões Regionais Brasileiras até 1941.

\begin{tabular}{|c|c|c|c|c|c|}
\hline $\begin{array}{l}\text { Autores } \\
\text { das } \\
\text { divisões } \\
\text { regionais }\end{array}$ & Ano & Critério & $\begin{array}{l}\text { Número } \\
\text { deregiões } \\
\text { estabelec } \\
\text { ida }\end{array}$ & $\begin{array}{l}\text { Regiões e seus } \\
\text { respectivos } \\
\text { estados }\end{array}$ & Observações \\
\hline $\begin{array}{c}\text { ÉliseeReclu } \\
\text { s }\end{array}$ & 1893 & $\begin{array}{l}\text { Geográf } \\
\text { ico- } \\
\text { Regioes } \\
\text { Naturais } \\
\text { (Bacias } \\
\text { Hidrogr } \\
\text { áficas) }\end{array}$ & 8 & $\begin{array}{l}\text { I Amazônia (AM e } \\
\text { PA) } \\
\text { II Vertente do } \\
\text { Tocantins (GO) } \\
\text { III costa Equatorial } \\
\text { (estados } \\
\text { nordestinos, do } \\
\text { Maranhão } \\
\text { Alagoas) } \\
\text { IV Bacia do são } \\
\text { Francisco e } \\
\text { Vertente Oriental } \\
\text { dos Planaltos (SE, } \\
\text { BA,ES e MG) } \\
\text { V Bacia do } \\
\text { Paraíba (RJ e DF) } \\
\text { VI Vertente do } \\
\text { Paraná é } \\
\text { Contravertente } \\
\text { oceânica (SP, PR } \\
\text { e SC) VI } \\
\text { VII Vertente do } \\
\text { Uruguai elitoral } \\
\text { adjacente (RS) } \\
\text { VIII Mato Grosso } \\
\end{array}$ & $\begin{array}{l}\text { Apresenta número excessivo de } \\
\text { regiões } \\
\text { Apego ao critério das Bacias } \\
\text { Hidrográficas }\end{array}$ \\
\hline $\begin{array}{l}\text { Delgado de } \\
\text { Carvalho }\end{array}$ & 1913 & $\begin{array}{l}\text { Geográf } \\
\text { ico- } \\
\text { Regioes } \\
\text { Naturais } \\
\text { e } \\
\text { Humana } \\
\text { s }\end{array}$ & 5 & 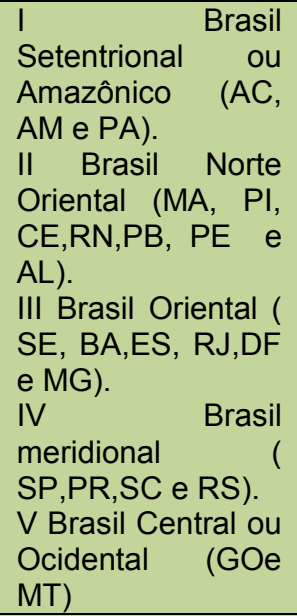 & $\begin{array}{l}\text { Divisão prática com fins didáticos } \\
\text { Sua divisão do Brasil em regiões } \\
\text { tornou-se clássica e exerceu uma } \\
\text { grande influência no ensino da } \\
\text { geografia nas primeiras décadas } \\
\text { do século atual) } \\
\text { Deu origem ao predomínio da } \\
\text { geografia física para explicar } \\
\text { aspectos humanos }\end{array}$ \\
\hline $\begin{array}{c}\text { Pe Geraldo } \\
\text { Pauwels }\end{array}$ & 1926 & $\begin{array}{l}\text { Geográf } \\
\text { ico- } \\
\text { Regioes } \\
\text { Naturais } \\
\text { (Vegeta } \\
\text { ção) }\end{array}$ & 6 & $\begin{array}{l}\text { I Amazônico } \\
\text { II Regiões das } \\
\text { Caatingas } \\
\text { III Planalto } \\
\text { Meridional } \\
\text { IV Litoral } \\
\text { V Região } \\
\text { Uruguaio- } \\
\text { Brasileira } \\
\text { VI IPlanície do } \\
\text { AltoParaguai ou } \\
\text { Grão-Chaco } \\
\text { Brasileiro }\end{array}$ & $\begin{array}{l}\text { Baseou-se, rigorosamente, na } \\
\text { geografia física utilizando como } \\
\text { critério predominante a vegetação }\end{array}$ \\
\hline Roy nash & 1926 & $\begin{array}{l}\text { Geográf } \\
\text { ico- }\end{array}$ & 6 & $\begin{array}{l}\text { I Altiplanos } \\
\text { Guianeses }\end{array}$ & $\begin{array}{l}\text { Baseou-se, rigorosamente, na } \\
\text { geografia física utilizando como }\end{array}$ \\
\hline
\end{tabular}




\begin{tabular}{|c|c|c|c|c|c|}
\hline & & $\begin{array}{l}\text { Regioes } \\
\text { Naturais } \\
\text { (Provínc } \\
\text { ias } \\
\text { Fisográf } \\
\text { icas) }\end{array}$ & & $\begin{array}{l}\text { II Planície } \\
\text { Amazônica } \\
\text { III Planalto Central } \\
\text { IV Cordilheiras } \\
\text { Marítimas } \\
\text { V Planície do Alto } \\
\text { Paraguai IPanície } \\
\text { VI IPlâneas } \\
\text { Litorân }\end{array}$ & $\begin{array}{l}\text { critério predominante o relevo } \\
\text { (províncias fisiográficas) } \\
\text { Não figura a região do Nordeste, } \\
\text { uma das mais características } \\
\text { regiões do país }\end{array}$ \\
\hline $\begin{array}{l}\text { Conselho } \\
\text { Nacional de } \\
\text { Estatística }\end{array}$ & 1938 & $\begin{array}{l}\text { Regiões } \\
\text { Naturais } \\
\text { (Posiçã } \\
\text { o } \\
\text { Geográf } \\
\text { ica) }\end{array}$ & 5 & $\begin{array}{l}\text { I } \\
\text { (AS,AM,PA, MA E } \\
\text { PI) Nordeste } \\
\text { II N } \\
\text { CE,RN,PB,PE e } \\
\text { AL) } \\
\text { III Este ( SE, BA e } \\
\text { ES) } \\
\text { IV Sul ( RJ,DF,SP, } \\
\text { PR,SC e RS) } \\
\text { V Centro-Oeste } \\
\text { (Go e MT) }\end{array}$ & $\begin{array}{l}\text { Esta divisão fixou normas para a } \\
\text { elaboração doAnuário estatístico, } \\
\text { baseada na divisão do Ministério } \\
\text { da Agricultura }\end{array}$ \\
\hline $\begin{array}{l}\text { Conselho } \\
\text { Nacional } \\
\text { Técnico de } \\
\text { Economia e } \\
\text { Finanças }\end{array}$ & 1939 & $\begin{array}{l}\text { Geográf } \\
\text { ico } \\
\text { (Zonas } \\
\text { Econôm } \\
\text { icas) }\end{array}$ & 5 & $\begin{array}{l}\text { l } \\
\text { (AS,AM,PA, MA E } \\
\text { PI) } \\
\text { II Nordeste } \\
\text { CE,RN,PB,PE e } \\
\text { AL, SE e BA) } \\
\text { III Sudeste } \\
\text { ES,RJ,DF,MG E } \\
\text { SP) } \\
\text { IV Sul (PR,SC e } \\
\text { RS) } \\
\text { V Centro-Oeste } \\
\text { (GO e MT) }\end{array}$ & $\begin{array}{l}\text { As zonas geoeconômicas não } \\
\text { correspondem, e nem poderiam, } \\
\text { as regiões naturais }\end{array}$ \\
\hline $\begin{array}{l}\text { Conselho } \\
\text { Nacional de } \\
\text { Geografia }\end{array}$ & 1941 & $\begin{array}{l}\text { Geográf } \\
\text { ico - } \\
\text { Regiões } \\
\text { Naturais }\end{array}$ & 5 & $\begin{array}{l}\text { I } \\
(A S, A M, P A, M A \\
P I) \\
\text { II Nordeste ( } \\
\text { CE,RN,PB,PE e } \\
\text { AL) } \\
\text { III Leste } \\
\text { (SE,BA,MG,ES,RJ } \\
\text { e DF) } \\
\text { IV Sul (SP,PR,SC } \\
\text { e RS) } \\
\text { V Centro-Oeste } \\
\text { (GO e MT) }\end{array}$ & $\begin{array}{l}\text { Fins práticos para o governo e a } \\
\text { Administração Pública. } \\
\text { Complementada em } 1945 \\
\text { Resolução n } 297 \text { do CNG, de } \\
23 / 0745) \text { quando, além da } \\
\text { inclusão dos territórios criados em } \\
1943 \text {, foram estabelecidos os } 4 \\
\text { níveis hierarquizados de regiões: } \\
\text { as cinco "grandes regiões" foram } \\
\text { decompostas em } 30 \text { "regiões", } \\
\text { por sua vez divididas em } 79 \text { "sub- } \\
\text { regiões" que eram subdivididas } \\
\text { em } 228 \text { "zonas fisiográficas". }\end{array}$ \\
\hline
\end{tabular}

Retirado de Bezzi (2004)

No entanto, nem sempre houve predominância dos critérios naturais para as delimitações regionais antes da institucionalização oficial $\mathrm{CNG}^{5}$. Por exemplo, nessa série histórica apresentada no Quadro 1 destaca-se a regionalização de Delgado de Carvalho, realizada em 1913. Ela é constituída

\footnotetext{
${ }^{5}$ Em 1934 foi criado o Conselho Nacional de Estatística (CNE) e em 1937 o Conselho Nacional de Geografia, a partir do Decreto $n^{\circ}$ 238/1938. Esses dois conselhos foram agrupados e receberam a denominação Instituto Brasileiro de Geografia e Estatística. Acerca da criação do IBGE, consultar Penha (1993). Disponível em: <http://biblioteca.ibge.gov.br/visualizacao/monografias/GEBIS\%20\%20RJ/ColecaoMemorialnstitucional/04-A\%20Criacao\%20do\%20IBGE.pdf>.
} 
por elementos de outras regionalizações e traz avanços no que diz respeito aos critérios para sua delimitação, ao se embasar em elementos naturais e socioeconômicos. Essa regionalização foi resgatada por Fábio Guimarães, encarregado de realizar estudos junto à comissão do IBGE, para a proposição de uma regionalização oficial para o país.

Por que, naquele momento, era importante pensar em uma regionalização oficial para o Brasil?

$\mathrm{Na}$ tentativa de apontar elementos que nos possibilitam a reflexão do questionamento, é preciso analisar a produção do espaço nos anos de 1930, período da instituição do Estado Novo, em que houve uma forte centralização das diretrizes políticas. Nesse bojo, era fundamental para o governo federal pensar o território a partir de um único recorte reconhecido por todas as instituições.

Nesse contexto, coube ao IBGE, em especial à coordenação de Fábio de Macedo Soares Guimarães, elaborar uma regionalização para o país. Várias propostas foram analisadas pela comissão de Fábio Guimarães, mas a selecionada com alguns ajustes foi a elaborada por Delgado de Carvalho, largamente utilizada nos livros didáticos e no cotidiano identitário dos brasileiros.

A regionalização de Delgado Carvalho baseou-se na trilogia aspectos naturais, humanos e econômicos, para identificar as paisagens. Eram, então, esses os aspectos utilizados para analisar o território, porém de forma pontual e fragmentada. Ainda hoje se observa a utilização dessa trilogia em algumas pesquisas. Na análise de Magnago (1995, p. 68), a opção de Fábio Guimarães pela regionalização de Delgado de Carvalho foi baseada em alguns aspectos de uniformidade para os grandes recortes e de uma regionalização que poderia ser utilizada por um longo período:

[...] a posição geográfica para nomear as Grandes Regiões e encontrava, também, o embasamento para definir as mesmas nas condições naturais do território. Prevalecia, dentro de um quadro de inter-relações das condições físicas, principalmente do clima, da vegetação e do relevo a noção de fato dominante - a chamada nota característica da região. 
A primeira regionalização oficial de 1941 sofreu algumas adaptações em virtude das modificações territoriais ${ }^{6}$. No entanto, o que se destaca na primeira regionalização são as diferenças de critérios metodológicos. Se, por um lado, nas fontes de pesquisas se conhece a importância dos critérios naturais como "fator dominante" para a delimitação da regionalização referente ao recorte das Grandes Regiões Brasileiras (Fig. 1), por outro, nas zonas fisiográficas, como apontado por autores como Bezzi (2204), Magnago (1995) Correa (1987), se percebe que foram utilizados elementos socioeconômicos como definidores, portanto com uma perspectiva de região diferente daquela da região natural.

A região geográfica, sobretudo na perspectiva da matriz da geografia francesa, foi estruturada com premissas dos elementos humanos, tais como formas de habitação, tipos de produção de trabalho entre outros. Na estruturação das zonas fisiográficas da divisão regional brasileira consideraram-se a inter-relação do quadro natural (clima, vegetação, formas de relevo) e a predominância dos fatos humanos (tipos de produção) que modificaram o território, constituindo os elementos estruturadores - ou seja, o fator dominante.

É possível inferir que as discordâncias em relação à primeira regionalização oficial, proposta para o Brasil, apoiaram-se na fragilidade dos critérios metodológicos. Para as grandes unidades foram utilizados critérios naturais, isto é, elementos situados numa vertente determinística, e para as menores unidades, as zonas fisiográficas, os aspectos socioeconômicos. Em termos metodológicos, Correa (1987) e Magnago (1995) afirmaram que essas fragilidades poderiam alterar inclusive os próprios recortes propostos, haja vista que critérios socioeconômicos possuem uma dinâmica espacial múltipla ao longo do tempo podendo vir a apresentar significativas variações.

Essa primeira regionalização esboça a preocupação de delimitar e centralizar as decisões políticas. Se anteriormente era possível identificar

\footnotetext{
${ }^{6}$ As modificações inseridas foram oficializadas em 1945, por meio da Resolução 297 do CNG de 1945, que, além de incluir os territórios criados em 1943, estabeleceu os quatro níveis hierarquizados de regiões: cinco grandes regiões, decompostas em 30 regiões, 79 sub-regiões e 228 zonas fisiográficas. As zonas fitográficas eram constituídas por municípios que apresentavam semelhanças sociais e econômicas (Bezzi, 2004, p. 287).
} 
arquipélagos e movimentos separatistas, o contexto político da primeira regionalização confirma a centralidade do Estado nas diretrizes e investimentos em fragmentos do território brasileiro. Somente a partir dessa articulação de relações de poder é possível ver a centralidade do território como constituidor de relações múltiplas de poder em diversas escalas, em que o aporte realanalítico do conceito de região expressa a ação dessas relações. Portanto, as regionalizações envolvem a articulação dessas relações de poder. ${ }^{7}$

Figura 018- - Divisão Regional IBGE - 1945

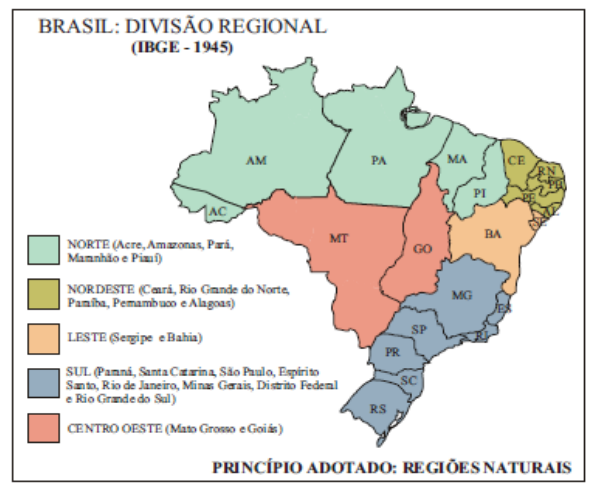

Figura 02 Divisão Regional IBGE 1969/1970

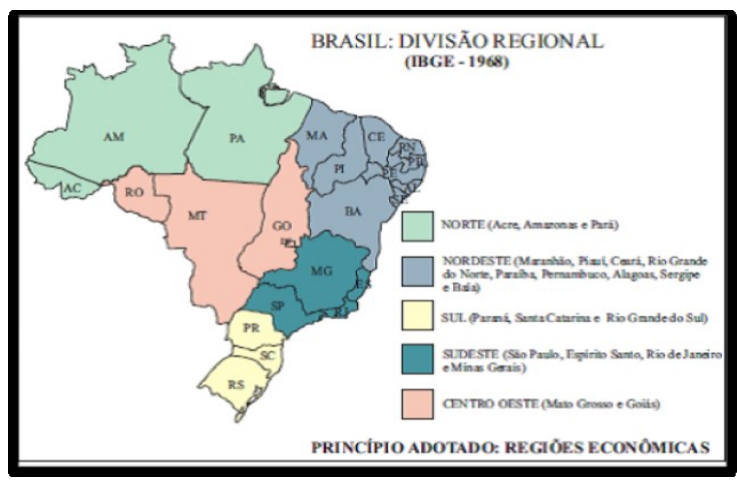

Essa primeira regionalização perdurou até meados de 1969, ano em que foi instituída uma nova divisão regional. É preciso contextualizar os 27 anos que separam essas regionalizações, em virtude dos avanços da ciência, em especial da ciência geográfica, dada a inserção de alguns elementos do positivismo lógico. Nas análises geográficas com viés neopositivista, foram estruturadas importantes criticas aos pressupostos da matriz clássica e ao método regional. Os geógrafos neopositivistas alegavam que os pesquisadores da matriz clássica e do método regional aprimoraram a observação e a descrição, mas não explicaram os fatos a partir do estabelecimento de leis.

Contribuíram para a compreensão das regiões como sistemas abertos e, nessa perspectiva, o espaço passa a ser analisado a partir das entropias e da isotropia - o aporte metodológico da Nova Geografia e o rigor linguístico

\footnotetext{
${ }^{7} \mathrm{Na}$ segunda seção do artigo é possível especializar a forma-conteúdo, em certa medida, fragmentada, concentradora e desigual dessas ações a partir das duas políticas analisadas.

${ }^{8}$ A primeira regionalização oficial ocorreu em 1941. No ano de 1945 foram realizadas algumas modificações em virtude de novas inserções territoriais (Fig. 01). As Figuras 01, 02, 03 e 05 foram retirados do site Observatório Geográfico de Goiás. <http://portais.ufg.br/sites/iesa observatoriogeogoias/pages/29802 >
} 
com os protótipos teóricos. Também contribuíram a linguagem matemática (os postulados e axiomas), o fisicalismo e o fisicismo como preceitos filosóficos, isto é, o fisicismo com os modelos teóricos e aplicação de leis gravitacionais com aporte da Física. Nesse contexto de novos conhecimentos científicos e das novas formas de produção, houve a necessidade de repensar 0 ordenamento territorial. Acerca do assunto Magnago (1995, p. 74) afirma:

As novas tendências no pensamento regional, muito voltadas para a questão do planejamento, estavam inseridas no conjunto de transformações socioeconômicas desencadeadas após a II Guerra Mundial. A maneira como vinha-se dando a expansão capitalista, desde o final daquele conflito, com suas inevitáveis consequências na produção de novas formas de organização do espaço brasileiro, acentuava a necessidade de reformulação do modelo de divisão regional do país.

Os pressupostos da Nova Geografia influenciaram as pesquisas brasileiras. Destacamos que as pesquisas e contribuições de aprimoramento de métodos e metodologias foram publicadas na Revista Geográfica do IBGE (RBG). Houve também a contribuição de pressupostos metodológicos para a nova regionalização do IBGE 1969/1970, como os pressupostos da hierarquização/influência das regiões funcionais/nodais brasileiras.

Para Faissol (1975), foram feitas análises baseadas em metodologias como as da Teoria dos Grafos, da Teoria de Berry, da Teoria da Cadeia de Markov, relacionando-as com as metodologias da Teoria dos Lugares Centrais. Em suma, nos anos de 1960-1970 o aporte metodológico da ação de regionalizar fundamentou-se nas teorias e modelos da Economia Espacial. Veja-se a explicação dada por Faissol (1975, p. 86) acerca disso:

A Região Funcional no contexto do conceito de região - [...] podem ser formadas segundo dois princípios básicos de homogeneidade de atributos de lugares e de relações entre lugares. O primeiro, ligado à própria noção de atributos intrínsecos do lugar (lugar aí tomado como um agregado previamente especificado em termos de extensão territorial e um conjunto de atributos do mesmo); o segundo, baseado no princípio básico da complementaridade que,de alguma forma, resulta das diferenças que existem entre lugares, e que por isso mesmo torna os lugares dependentes uns dos outros, isto é, interdependentes entre si. Esta complementaridade é que gera o sistema de relações, obviamente assimétricas e consequentemente de natureza hierárquica. $O$ problema é aparentemente simples, mas implica na necessidade de especificar adequadamente os dois sistemas: uma matriz que descreva os atributos dos lugares nas colunas e os lugares nas linhas e relações especificas entre estes pares de lugares nas colunas. O problema que se coloca é se as 
relações que os lugares mantêm com outros lugares são propriedades destes e, portanto, expressas na mesma matriz de atributos, ou se as relações dependem de um sistema de decisões, no qual das propriedades dos lugares são essenciais, mas não determinantes. Parece óbvio que se pode argumentar em favor da segunda hipótese seguindo a linha da Theory Berry.(FAISSOL, 1975,p. 86)

Nesse sentido, o incentivo pela reestruturação e desenvolvimento das regiões brasileiras foi fomentado por políticas regionais que instituíram as superintendências de desenvolvimento regional, como a Superintendência de Desenvolvimento da Amazônia (SUDAM) em 1966, a Superintendência de Desenvolvimento do Centro-Oeste (SUDECO) em 1967, e a Superintendência de Desenvolvimento da Região Sul (SUDESUL) em 1969, entre outras. A tentativa era promover uma política de enfrentamento das desigualdades e desenvolvimento regional.

Portanto, não eram mais os elementos naturais e humanos que definiam os pressupostos da região como fatores dominantes. Para a formulação dos pressupostos e dos princípios das regionalizações já se associavam teorias aplicadas e testadas. A partir desses novos pressupostos, foram constituídos os elementos definidores de uma região, assim como as ações de regionalizar. Da análise comparativa das duas regionalizações do IBGE (1941 e 1969) podem-se perceber algumas diferenças na metodologia nos elementos utilizados para a definição da ação de regionalizar.

Nesse sentido, as diferenças são visíveis em comparação com os grandes recortes regionais. Por exemplo, a região Sudeste não constituía uma região e seus estados anteriormente integravam a região Sul, com base nos elementos naturais. Somente a partir da regionalização de 1969/1970 a região Sudeste foi delimitada como uma Grande Região, adotando-se critérios baseados nas análises espaciais de funcionalidade das variáveis econômicas desse espaço em correlação com a projeção econômica do sistema de relações e polarização dos fluxos. Daí a necessidade de articulação do par homogeneidade-funcionalidade.

Nos anos de 1960-1970, ao lado das propostas para a nova regionalização oficial (1969), houve, também, as que propunham a 
regionalização a partir de sua funcionalidade. Por exemplo, a regionalização proposta pelo geógrafo Pedro Pinchas Geiger (1969) foi elaborada a partir das variáveis da divisão territorial do trabalho, especialização dos setores produtivos brasileiros que, nos anos de 1970, eram fortemente acentuados pelo modelo industrial.

Em termos metodológicos, Geiger (1969) (Fig. 3) correlacionou os critérios socioeconômicos que homogeneízam, polarizam, hierarquizam as regiões a partir das contradições que marcaram o desenvolvimento desigual nas regiões. A partir disso, elaborou uma regionalização para o Brasil em três macrorregiões geoeconômicas: Amazônia, Nordeste e Centro-Sul. Os limites das macrorregiões propostas por Geiger são relacionados aos construtos de polarização e hierarquização. Assim, há fragmentos de municípios e unidades federativas que pertencem às duas macrorregiões.

Segundo Magnago (1995), o espaço, e consequentemente a ação de regionalizar, é permeado pela organização do homem, o que leva em consideração variáveis como recursos naturais e sua utilização ou escassez, concentração e especificação da produção, estrutura social, pagamentos interregionais. Outra regionalização baseada nos critérios econômicos foi desenvolvida pela geógrafa Bertha Becker (1972), que apresentou a estrutura espacial brasileira hierarquizada em centro-periferia.

[...] o sistema espacial se integra através de uma estrutura de relações de autoridade-dependência exercidas a partir de grandes cidades, foco inicial das inovações. Os centros inovadores constituem core regions ou centros; todas as outras áreas de sistema espacial são regiões periféricas, definidas por suas relações de dependência com a core region.

A partir das análises dos fluxos regionais da produção, Becker (1972) fez uma espacialização com base nas hierarquias urbanas, na centralidade dos elementos polarizadores que influenciaram fragmentos do território brasileiro. Nesse sentido, apresentou uma regionalização marcada pela estrutura centroperiferia estruturada nas relações entre infraestrutura, fluxos e integração (Fig. $4)$. 
Figura -03 -Divisão Regional Pedro Geiger 1967

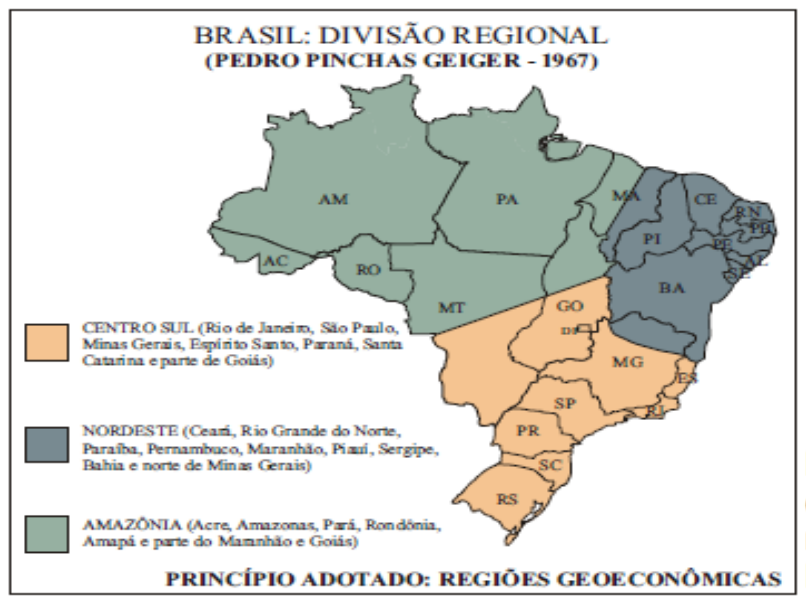

Figura 04- Complexos GeoEconômicosBertha Becker

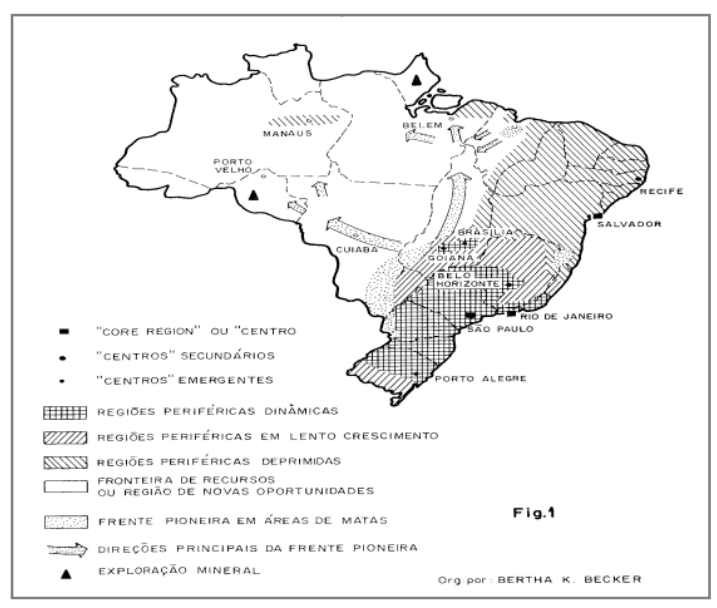

Fonte: Fig 03, Borges (2002) e Fig 04 Becker, B (1975)

No ano de 1972, o IBGE iniciou os estudos das regiões funcionais urbanas com base nas hierarquias e influências das cidades brasileiras, com destaque para a concentração produtiva e da pobreza nas metrópoles. Para Magnago (1995, p. 82), a importância dos estudos de hierarquias urbanas potencializou uma leitura do território que permitiu a ação de políticas públicas mais eficientes:

[...] um sistema hierarquizado de divisões territoriais e de cidades que podem servir de modelo tanto para uma política regionalizada de desenvolvimento, como para orientar a racionalização no suprimento de serviços de infraestrutura urbana através da distribuição mais adequada.

As metodologias utilizadas para o estudo das regiões funcionais urbanas foram avaliadas no ano de 1978 e publicadas novamente no ano de 1987, intitulando-se Regiões de Influência das Cidades (REGIC). A metodologia baseou-se nos estudos de Michel Rochefort, que analisou a estrutura das regiões francesas baseando-se na influência dos centros e na especialização da rede de fluxos. Para o estudo das Regiões de Influência das Cidades, a estruturação da base de dados foi feita em colaboração com o EPEA (atual IPEA). 


\begin{abstract}
A base de dados analisada foi o Inquérito Municipal CNG/EPEA de1966. O questionário, elaborado em colaboração com o então Escritório de Pesquisa Econômica Aplicada e preenchido pelos Agentes Municipais de Estatística do IBGE, foi aplicado em todos os municípios com população superior a 10.000 habitantes; tinha como foco a identificação dos lugares onde a população do município buscava bens e serviços não ofertados naquele município e apresentava-se dividido em 135 itens agrupados em quatro capítulos: I - Atividade agrícola e extrativa vegetal; II - Pecuária; III Atividade comercial; e IV - Saúde, educação, estabelecimentos bancários, transporte e comunicações. (IBGE/REGIC, 2008, s.p.).
\end{abstract}

No ano de 1993 foram realizados novos estudos da REGIC, apenas publicados no ano de 2000. As análises incidiram na dinâmica dos anos de 1990, período marcado pela descentralização política, pela questão municipalista e pela forte competição fiscal e produtiva entre entes da federação. Nos anos de 1990 é possível observar-se a consolidação do papel das redes, sobretudo, as redes informacionais. Nesse sentido, no estudo publicado da REGIC 2008 é possível identificar apontamentos que diferenciam a pesquisa do ano de 1978 para a de 1993:

Duas questões emergem dos estudos anteriores, com reflexos na elaboração do presente trabalho. De um lado, o estudo de 1978 refere-se, em várias Unidades da Federação, a "um papel relevante [do] Estado como promotor da ascensão hierárquica da capital" (REGIÕES..., 1987, p. 22); de outro, análises empreendidas no âmbito do estudo de 1993 apontam a relativa dissociação que se estabelece entre a hierarquia dos bens e serviços oferecidos e a hierarquia urbana, refletindo as transformações socioeconômicas e espaciais que fazem com que funções de alto nível passem a ser encontradas em centros de hierarquias mais baixa. (IBGE/REGIC, 2008, s.p.).

No estudo da REGIC de 2008 (Fig. 5) as mudanças na metodologia visaram uma melhor espacialização das transformações na dinâmica das redes urbanas no Brasil. Num primeiro momento foram classificados os centros e sua área de influência retomando o estudo de Divisão Regional do IBGE de 1972. 


\section{Figura 05: Regiões de Influência das Cidades - 2008}

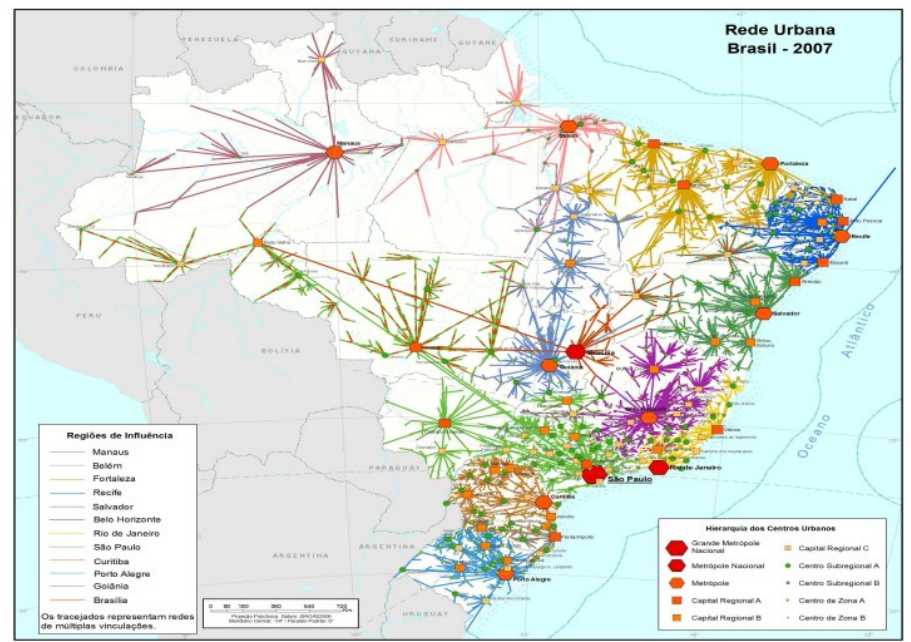

Fonte: IBGE/REGIC (2008)

$\mathrm{Na}$ segunda etapa, a análise foi baseada em dados secundários de órgãos das unidades federativas e entes privados. Com esses dados foram estabelecidos níveis de centralidade: administrativo, jurídico e econômico. Essa segunda etapa possibilitou apreender as dinâmicas de novos centros que anteriormente não foram identificados. A partir das análises complementares desses dados secundários foram acrescentados elementos referentes aos equipamentos e serviços. Com essa correlação se definiram os núcleos de gestão do território. Após a hierarquização dos núcleos de gestão do território, correlacionaram-se as análises entre as cidades, para identificação do grau de articulação e hierarquização das redes ${ }^{8}$.

\footnotetext{
Uma vez delimitadas as regiões de influência, verificou-se que o conjunto de centros urbanos com maior centralidade - que constituem foco para outras cidades, conformando áreas de influências mais ou menos extensas - apresenta algumas divergências em relação ao conjunto dos centros de gestão do território. Neste último, há casos de atuação restrita ao próprio território, exercendo funções centrais apenas para a população local. Inversamente, há cidades não incluídas naquele conjunto cuja centralidade foi identificada a partir do efeito polarizador que exercem sobre outras. A etapa final consistiu na hierarquização dos centros urbanos, para a qual foram elementos importantes a classificação dos centros de gestão do território, a intensidade de relacionamentos e a
}

\footnotetext{
${ }^{8}$ As informações foram extraídas da publicação IBGE/REGIC 2008.
} 
dimensão da região de influência de cada centro. Os municípios e as áreas de concentração de população foram as unidades territoriais que constituíram o universo do estudo. (REGIC, 2008, s.d.).

Com a influência de teorias e modelos fortemente apoiados na Economia Espacial, identificam-se avanços e novas possibilidades de pesquisas baseadas em novas variáveis, fluxos econômicos e sua dinâmica no território, em correlação com as hierarquias das redes urbanas. Dentre essas pesquisas, se destacam as que levaram em consideração a necessidade de se espacializar o território brasileiro a partir da divisão territorial do trabalho. Para tanto, embasaram-se nos elementos de homogeneidade-funcionalidade, centro-periferia, o que possibilitou avanços nas ações de regionalização e da produção desigual-combinada no/do território brasileiro.

Pedro Geiger e Bertha Becker, entre outros, analisaram e estruturaram metodologicamente as ações regionalizadoras levando em consideração os novos processos que transformaram a dinâmica brasileira na década de 19701980, como, por exemplo, a efervescência de fatores político-econômicos, a crise dos anos de 1980, o processo de abertura a redemocratização. Esses processos marcaram a dinâmica brasileira e foram correlacionados às análises de elementos críticos da geografia.

Os trabalhos de Santos (1978) trouxeram contribuições para um repensar das bases teóricas da ciência geográfica e a análise do território brasileiro como totalidade. Em 2001, Santos apresentou uma regionalização estruturada à luz dos pressupostos do materialismo dialético, em que relaciona o processo histórico de formação dos complexos regionais e os aspectos do meio técnico-científico informacional, propondo uma regionalização em quatro complexos: Região Concentrada, Região Centro-Oeste, Região Nordeste e Região Amazônica. 


\section{Figura 06 - Regionalização Milton Santos}

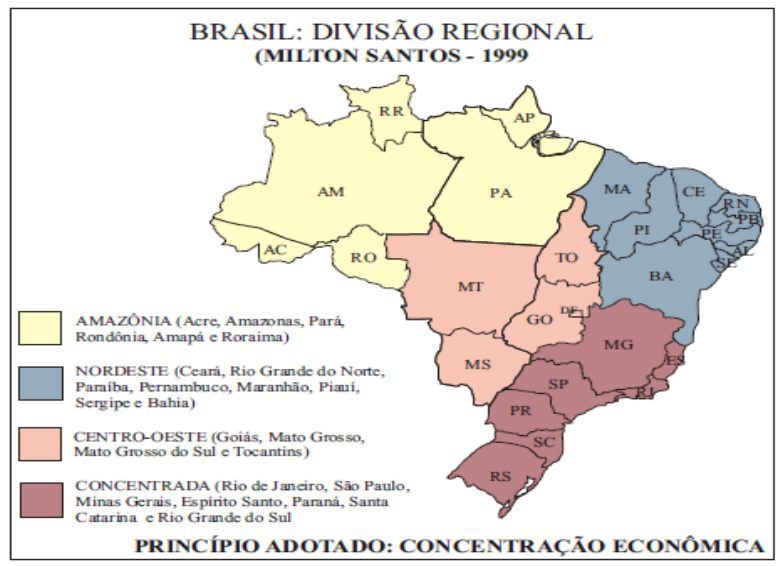

Nessa profusão de relações de poder, a regionalização oficial do IBGE de 1969/1970 foi repensada diante das fragilidades em apreender a dinâmica da estrutura brasileira do final dos anos de 1980. O início dos anos de 1990 apresentava novos elementos para espacializar os processos econômicos e políticos, com o aprofundamento da globalização e a conexão de território em redes técnicas-informacionais.

Magnago (1995, p. 85) assinala que no ano de 1988 o IBGE repensou a estrutura da divisão regional, em especial das mesorregiões e microrregiões, propondo uma metodologia baseada em critérios estruturantes do processo social, ou seja, nos eixos econômicos que estruturam o território nacional na escala da mesorregião, porém a partir das Unidades Federativas e não mais da homogeneidade.

Diferentemente do modelo anterior que partia da agregação de áreas
segundo critérios de homogeneidade, a metodologia adotada nesses
estudos apoiava-se na noção de totalidade nacional, tomando as
Unidades da Federação como universo de análise, Através do
método de divisão sucessiva desses espaços - as UFs -
identificaram-se, posteriormente, as mesorregiões e microrregiões
que passaram, então, a ter denominação de geográficas em lugar de
homogêneas.

A revisão da regionalização do IBGE nos anos de 1989/1990 foi realizada para as mesorregiões e microrregiões. A estruturação das Grandes Regiões ainda é representada pelos critérios da regionalização de 1969/1970. 
Nos critérios utilizados para a reavaliação do ordenamento territorial brasileiro para as mesorregiões geográficas na regionalização de 1989/1990 levou-se em consideração o processo social como determinante, os aspectos físicos como condicionantes, a influência das redes de comunicação e a sua articulação espacial. E para as microrregiões, os critérios foram as especificidades da estrutura produção, quais sejam, as articulações das estruturas industriais, a agropecuária, o extrativismo, entre outros (IBGE, 2008a).

\section{Quadro 02 Dimensões de Identificação das Mesorregiões e}

\section{Microrregiões do IBGE 1989/1990}

\begin{tabular}{|l|l|}
\hline \multicolumn{1}{|c|}{ Mesorregiões } & \multicolumn{1}{c|}{ Microrregiões } \\
\hline $\begin{array}{l}\text { Processos Sociais e Condicionantes do do } \\
\text { Quadro Natural: história social, povoamento, } \\
\text { estudos geográficos,mapas e documentação } \\
\text { específica }\end{array}$ & $\begin{array}{l}\text { Estrutura da Produção Primária: uso da terra, } \\
\text { orientação da agricultura, estrutura } \\
\text { dimensional dos estabelecimentos, relações } \\
\text { de produção, nível tecnológico e emprego de } \\
\text { capital, grau de diversificação da produção } \\
\text { agropecuária }\end{array}$ \\
\hline $\begin{array}{l}\text { Rede de Comunicação e Lugares: área de } \\
\text { influência dos centros metropolitanos e e } \\
\text { regionais; mapas rodoviários (DNER) e de } \\
\text { comunicação }\end{array}$ & $\begin{array}{l}\text { Estrutura da Produção Industrial: valor da } \\
\text { transformação industrial e pessoal ocupado }\end{array}$ \\
\cline { 2 - 2 } & $\begin{array}{l}\text { Interação Espacial: área de influência dos } \\
\text { centros sub-regionais e centros de zona }\end{array}$ \\
\hline
\end{tabular}

Fonte: IBGE (2008a) Org: França, K (2012)

A partir desse resgate histórico dos elementos, critérios e metodologias utilizados para a ação de regionalizar o território brasileiro, observa-se que o ato de recortar o território envolve conexões com o processo empreendido na realidade, embora seja uma representação desta. Portanto, as regionalizações representam ações de poder que propiciaram o ordenamento do território para além de melhor administrá-lo. Para Limonad (2004, p. 58), as regionalizações para um mesmo território

[...] são inúmeras e usualmente atendem a interesses extremamente precisos e este, parece-nos, é um primeiro ponto a não se perder de vista. Há que se considerar, ainda, que as regionalizações podem emergir da análise e reflexão conforme se destaquem ou não determinados elementos e fatores. Uma regionalização pode servir de base a propostas de desenvolvimento regional. Propostas estas cujo caráter irá variar conforme os objetivos a que se propõe atender. 
No século XXI há diversas regionalizações, estruturadas por diferentes critérios, baseados nas políticas públicas setoriais. Para cada uma das propostas de políticas públicas apresentam-se distintos recortes de regionalizações. As regionalizações são realizadas não apenas pelas diretrizes nacionais, mas pelas Unidades Federativas e municípios, a partir de suas ações expressas nos planos plurianuais, dentre outros programas. Além das regionalizações dos setores privados, as diversas regionalizações empreendidas no âmbito municipal são associadas, em certa medida, com a autonomia municipal, instituída pela Constituição Federal de 1988.

Em relação à regionalização oficial, o IBGE no ano de 2008 realizou alguns seminários para atualizar a divisão regional do Brasil, no sentido de sistematizar a conexão da base de dados com a dinâmica das transformações socioeconômicas, em virtude dos novos elementos que passaram a dimensionar a dinâmica brasileira. No entanto, ainda não ocorreu uma análise aprofundada para a disponibilização de uma nova regionalização.

Vale dizer que a atualização da regionalização implica reconhecer os novos agentes que ordenam o território brasileiro e elaborar novos critérios para que se possa apreender a diversidade e complexidade das relações que estruturam e produzem o território. Nesse contexto, é salutar analisar algumas regionalizações de políticas públicas ou programas de fomento ao desenvolvimento que empreendem novos recortes regionais e critérios que impactam na eficiência e efetividade dos objetivos expressos nas políticas públicas.

A seguir apresenta-se um quadro com algumas políticas públicas que foram elaboradas levando em consideração a regionalização do IBGE para as mesorregiões e microrregiões geográficas. 


\section{Quadro 03: Divisões Regionais e Usos a partir das Políticas} Públicas

\begin{tabular}{|c|c|}
\hline Programas & $\begin{array}{c}\text { Tipologia da Regionalização } \\
\text { Observações }\end{array}$ \\
\hline $\begin{array}{l}\text { Política Nacional de Desenvolvimento } \\
\text { Regional }\end{array}$ & $\begin{array}{l}\text { A PNDR levou em consideração os recortes } \\
\text { oficias das mesorregiões e microrregiões } \\
\text { geográficas correlacionado esses recortes a } \\
\text { partir de duas variáveis renda domiciliar e } \\
\text { variação do PIB, para elaborar as diferentes } \\
\text { estratégias de intervenção da política } \\
\text { pública. A partir dessas variáveis e de } \\
\text { técnicas de reagrupamento a PNDR } \\
\text { apresenta uma tipologia regional síntese em } \\
\text { quatro conjuntos territoriais com distintos } \\
\text { níveis de atuação. Nesses quatro grandes } \\
\text { recortes existem sub-regionalizações das } \\
\text { microrregiões geográficas hierarquizadas a } \\
\text { partir das duas variáveis }\end{array}$ \\
\hline Plano Nacional de Logística de Transportes & $\begin{array}{l}\text { Critério homogeneidade econômica a partir } \\
\text { da correlação de cinco vetores: 1- produção; } \\
\text { 2- deslocamento nos acessos aos mercados } \\
\text { de exportações; } 3 \text { - sociedade; } 4 \text {-tecnologia } \\
\text { e inovação e } 5 \text { - convergência dos gargalos } \\
\text { Vetores Logísticos: Macrorregional, } \\
\text { microrregional,corredores de transportes, e } \\
\text { sustentabilidade ambiental. A partir dessa } \\
\text { correlação a PNLT é estruturada em vetores } \\
\text { regionais sendo eles: Amazônico, Centro- } \\
\text { Norte, Leste,Nordeste Setentrional, Nordeste } \\
\text { Meridional, Centro-Sudeste e Sul. Esses } \\
\text { vetores necessariamente não correspondem } \\
\text { a regionalização oficial do IBGE (1989) em } \\
\text { relação ao vetor Sul e também esse vetores } \\
\text { são correlacionados aos vetores de } \\
\text { integração latino-americano. } \\
\text { Os indicadores para a espacialização desse } \\
\text { vetores foram: total do PIB, população total, } \\
\text { densidade por hab/km,, PIB per capita }\end{array}$ \\
\hline Zona Típica de Módulo - ZTM & $\begin{array}{l}\text { As ZTMs são delimitadas pelo INCRA a partir } \\
\text { das microrregiões geográficas do IBGE. As } \\
\text { ZTMs são delimitadas a partir da } \\
\text { homogeneidade dos critérios ecológicos e } \\
\text { econômicos das MRGs. }\end{array}$ \\
\hline
\end{tabular}

Fonte: IBGE (2008a) e Planos Setoriais. Org: França, K (2012)

É essencial atualizar a regionalização oficial de 1989, para possibilitar análises e intervenção no espaço que levem em consideração novas dimensões. As regionalizações subsidiam as estratégias de intervenção das políticas públicas (Quadro 3). Repensar a regionalização oficial e as diversas outras regionalizações a partir de critérios eficientes permite a alocação eficaz 
de investimentos e ações das políticas públicas e ao mesmo tempo proporciona a articulação dessas políticas, com ações intersetoriais calcadas em recortes regionais integradores.

As regionalizações administrativas representam uma regionalização historicamente construída normalmente tendo como base o conceito de região funcional. Embora as atualizações das regionalizações brasileiras agreguem novos critérios além da funcionalidade, Santos (1978) afirma que a regionalização construída historicamente se transforma numa rugosidade e poderá ser modificada ou descartada em virtude dos sistemas de engenharia. Acerca do assunto, Silva Neto (2003, p. 361) complementa que:

[...] as regiões historicamente construídas pelo processo de
povoamento e ocupação do território ou pela regionalização
institucional estariam se fragmentando para formar outros
agrupamentos regionais. Poderíamos chamá-los de regiões
"científico-técnico-informacionais", verdadeiros sistemas locais
projetados para funcionar como "máquinas" hardwares territoriais. A
modernização - tanto do ponto de vista técnico quanto ideológico -
seria a ideia motora dessas novas regionalizações. Isto está
subjacente, inclusive, no arcabouço normativo do Estado, onde os
atuais dispositivos constitucionais poderão levar igualmente à
fragmentação territorial.

A regionalização no período atual não se limita a repartir o território para melhor administrá-lo. As regionalizações realizadas são frutos de intervenção governamental nas esferas federal, estadual, municipal setor empresarial e tanto podem reduzir como acirrar as desigualdades regionais, já que elas derivam da racionalização do território.

Nesse sentido, analisam-se os avanços $e$ as fragilidades das regionalizações propostas nos Eixos Nacionais de Integração e Desenvolvimento (ENIDs) (1996) e na Política Nacional de Desenvolvimento Regional de 2003-2010, bem suas proposições para 2011-2015 (a segunda fase da PNDR).

A análise é feita a partir de três elementos norteadores:

- Caracterização geral da política;

- Metodologia de regionalização da política;

- Estratégia de ações 


\section{Caracterização geral dos Eixos Nacionais de Integração e Desenvolvimento (ENIDs)}

A década de 1990 foi marcada pela emergência do processo de abertura econômica, pela crise do modelo econômico fomentado na substituição das importações e pelo aprofundamento do processo de globalização. $O$ aprofundamento da revolução técnico-científico-informacional se coadunou aos preceitos neoliberais da desregulamentação da economia e consequentemente do planejamento regional, no qual o setor privado teve predominância na alocação de recursos.

No Brasil, os referidos preceitos transformaram o projeto neoliberal em uma marca do período de redemocratização do país. Os resultados das eleições presidenciais de 1989 e de 1994, que elegeram Fernando Collor e Fernando Henrique Cardoso, respectivamente, contribuíram para novas premissas do planejamento regional e, em certa medida, para as ações regionais fragmentadas e pontuais.

Autores como Bacelar (2000), Cano |(1998), Galvão e Brandão (2003) entre outros apresentam, em suas análises, os benefícios e fragilidades dos processos e das políticas brasileiras que fomentaram o desenvolvimento em escala regional. Em linhas gerais, Bacelar (2000) afirma a necessidade de elaboração de políticas regionais que não sejam (re)concentradoras e de desconstrução da tendência histórica de as políticas regionais no Brasil se pautarem em investimentos para as regiões ou fragmentos de regiões já consolidadas em termos de infraestrutura econômica.

Para repensar a atuação do planejamento regional e o fomento de programas que potencializem ou fortaleçam as infraestruturas e a capacidade de inovação da economia local foi necessário elaborar novos programas articulados à capacidade local, conectados à integração econômica nacionalinternacional.

Os ENIDs constituem uma política desenvolvida no governo do expresidente Fernando Henrique Cardoso, no contexto de substituição das superintendências de desenvolvimento, em virtude da ineficácia delas no 
fomento ao desenvolvimento regional e das novas diretrizes de planejamento regional nos anos de 1990, articuladas a objetivos de integração econômica e competitividade internacional. A principal premissa dos ENIDs era a necessidade de integrar e acirrar a competitividade brasileira no cenário global a partir do fomento ao desenvolvimento de corredores de exportação.

A valorização do aspecto de infraestrutura, sobretudo do setor de transporte, potencializou a elaboração dos eixos de desenvolvimento. A delineação dos ENIDs foi integrada ao primeiro mandato do presidente FHC, inserido no Plano Brasil em Ação.

O Programa Brasil em Ação, instituído em 1996, apresentava como metas principais a redução das desigualdades regionais e o fomento ao desenvolvimento conectado à competitividade global. Dentre as políticas criadas pelo programa, se destacam os ENIDs. As críticas aos ENIDs foram fomentadas pelas fortes estratégias de integração competitiva, que acirrou a fragmentação do território brasileiro e reduziu as ações para o enfrentamento das desigualdades regionais. Haja vista que apenas fragmentos do território já potencialmente articulados foram fortalecidos por investimentos, a partir dos cinco eixos de integração nacional e dois eixos continentais (Bacelar, 2000), a saber: 1 - Eixo de integração Norte-Sul; 2- Eixo de integração Oeste; 3 - Eixo de integração Nordeste; 4 - Eixo de integração Sudeste; 5 - Eixo de integração Sul; 6 - Saída para o Caribe; 7- Saída para o Pacífico.

A regionalização desses eixos (Fig. 7) permite inferir que, em certa medida, os eixos "nacionais" se conectavam aos corredores de exportação e o eixos continentais se conectavam às saídas para o Caribe e o Pacífico, na tentativa de integrar e articular o escoamento da produção via oceano Atlântico, o que reforça as ações de políticas para potencializar o fortalecimento da produção e escoamento com custos reduzidos (EGLER, 2001). 


\section{Figura 07: Eixos Nacionais de Integração e Desenvolvimento}

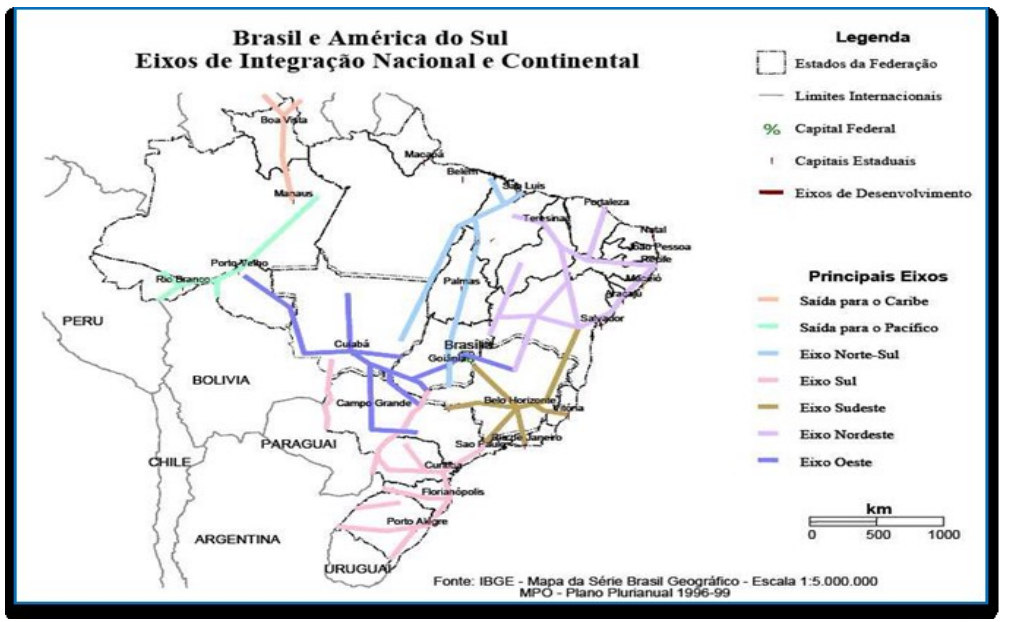

Fonte: Consórcio Brasiliana (1998)

No segundo mandato de FHC foram desenvolvidas novas análises para a viabilidade da implantação dos eixos, sob a coordenação do Banco Nacional de Desenvolvimento (BNDES), do Ministério do Planejamento, Orçamento e Gestão e do consórcio Brasiliana, responsável pelas análises em parceria com os dois órgãos governamentais. Egler (2001) ressalta que no segundo mandato de FHC a delineação dos eixos se diferenciava dos eixos propostos no primeiro mandato, a saber: Eixo da Amazônia;Eixo Araguaia-Tocantins/Ferrovia NorteSul Ferrovia Carajás;Eixo Nordeste; Eixo Oeste; Eixo Sudeste; Eixo Sul.

Nesse sentido, Galvão e Brandão (2003) analisaram os ENIDs como uma transformação nas diretrizes do desenvolvimento regional brasileiro. Anteriormente as premissas do desenvolvimento regional eram baseadas nas estratégias de ocupação do território e com os ENIDs as estratégias passaram a se calcar em premissas geoeconômicas, isto é, integração e competitividade econômica.

A valorização da infraestrutura econômica, principalmente a de transportes, que materializa o fluxo de produtos e pessoas, passou a ser definidora de eixos e de sua área de influência, para fins de planejamento integrado. Do ponto de vista do desenvolvimento, essa postura levou a uma posição secundária fatores como recursos naturais e outras potencialidades, a favor da infraestrutura como elemento essencial de sucesso. (GALVÃO; BRANDÃO, 2003, p. 173). 
$\mathrm{Na}$ regionalização dos ENIDs proposta no primeiro mandato de FHC havia articulações dos eixos nacionais e continentais. Na nova fase de estudos, com a redefinição das estratégias para os novos recortes dos eixos, notam-se sutis diferenças, sendo que nos eixos propostos no segundo mandato de FHC não distinguem recortes nacionais de internacionais e se potencializam nove eixos para o fomento às políticas de competitividade e fortalecimento global. ${ }^{9}$ Portanto, a efetividade da política dos ENIDs se estruturou num contexto de estagnação da competitividade econômica brasileira no cenário global e na necessidade de espacialização dos investimentos, para tornar a economia competitiva e estruturada no tripé "logística, infraestrutura e redução de custos" (ABLAS, 2003).

Figura 08: Eixos Nacionais de Integração e Desenvolvimento2000-2003

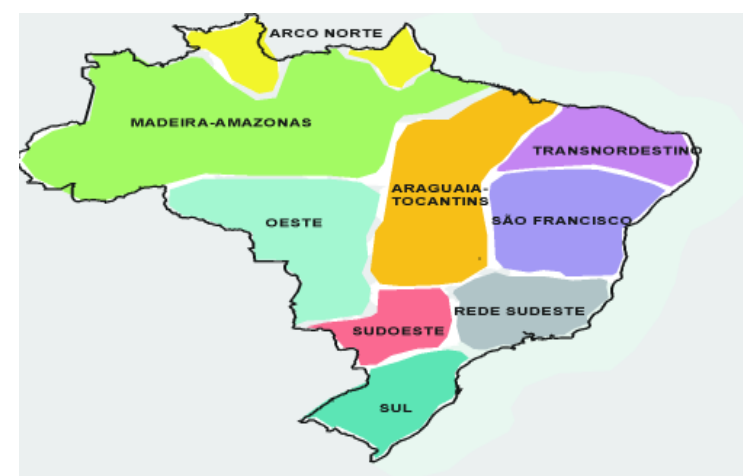

Fonte: Consórcio Brasiliana (1998)

$\mathrm{Na}$ política dos ENIDs há formulações importantes para os setores de infraestrutura e logística, no sentido de fortalecimento dos segmentos econômicos no Brasil após as fragilidades de sucessivos governos. No entanto, há fortes críticas às características e ações dos ENIDs no que diz respeito à sua efetividade como política regional. Bacelar (2000) afirma que os ENIDs configuraram uma estratégia do Estado em capitalizar e fomentar novos espaços para a integração econômica, o que agravou os investimentos em políticas regionais mitigadores de desigualdades.

\footnotetext{
9 Egler, no artigo "Eixos Nacionais de Integração de Desenvolvimento: impactos ambientais prováveis" (2001), aprofunda as diferenças Nos recortes dos ENIDS nos mandatos de FHC. Disponível em: <www.egler.com.br>.
} 


\title{
Metodologia e regionalização dos ENIDs
}

É importante ressaltar que a metodologia empreendida para a regionalização que estruturaram os eixos não foi baseada nos critérios das macrorregiões delineadas pelo IBGE. Sabe-se que essas macrorregiões são definidas pela continuidade dos espaços, considerando as redes de transporte para as projeções de interações em nível de mobilidade de pessoas e serviços hierarquizados.

A metodologia para a delimitação dos recortes espaciais dos ENIDs tem como referência a infraestrutura econômica, que fomentou um novo recorte regional para a atuação de políticas públicas.

Nesse sentido, o critério primordial para a espacialização dos recortes dos eixos nacionais foi a revisão da compreensão do significado de eixos. Os pressupostos de eixos, de acordo com a proposta técnica do Consórcio Brasiliana (1998, p. 10), são como segue:

\begin{abstract}
Eixo nacional de integração e desenvolvimento corresponde a um corte espacial composto por unidades territoriais contíguas, definidas com objetivos de planejamento, e cuja lógica está relacionada às perspectivas de integração e desenvolvimento consideradas em termos espaciais. Dois critérios devem ser levados em conta, tanto nessa definição, como na delimitação: i) a existência de rede multimodal de transporte de carga de alta capacidade, efetiva ou potencial, permitindo acessibilidade aos diversos pontos situados na área de influencia do eixo e, ii) possibilidades de estruturação produtiva interna, em termos de atividades econômicas que definem a inserção do eixo em um espaço mais amplo ( nacional ou internacional), inclusive com seus efeitos multiplicadores na sua área de influência. (Consórcio Brasiliana, 1998, p. 10).
\end{abstract}

As áreas de influência dos ENIDs foram delimitadas tomando como referência as interações e hierarquias das relações socioeconômicas estruturadas pelo sistema de transportes e hierarquias urbano-regionais que expressam a integração e o desenvolvimento. No caso da integração, enfatizando o acesso e a mobilidade de infraestrutura, serviços, comunicações que potencializem a fluidez de informações e serviços. No que diz respeito ao desenvolvimento, quanto à densidade das áreas de concentração no território brasileiro, com destaque para a concentração de pessoas e serviços nas metrópoles e regiões metropolitanas. 
Na delimitação dos eixos houve a preocupação em critérios para afirmar a coerência interna dos eixos em relação à produção, consumo e hierarquias. Para tanto, levaram-se em consideração as estruturas produtivas, os condicionantes de localização e as áreas do "entorno" dos eixos. Os seguintes critérios foram empregados para delimitação dos eixos:

- Fluxo de Transporte

- Hierarquia Funcional de Cidades

- Focos Dinâmicos

- Condicionantes Ambientais

- Distribuição Espacial da População

A delimitação dos critérios possibilitou o estabelecimento de importantes aspectos para a coerência interna dos eixos e a possibilidade de comparações entre eles, visando à eficácia de atuação das políticas públicas.

\section{Quadro 04: Diretrizes dos Aspectos para a caracterização dos Eixos}

\begin{tabular}{|c|l|}
\hline Dinâmica Econômica & $\begin{array}{l}\text { Atividades econômicas dominantes } \\
\text { Inovação e oportunidades de integração aos } \\
\text { principais vetores da economia doméstica. } \\
\text { Inserção econômica externa }\end{array}$ \\
\hline \multirow{3}{*}{ Aspectos Sociais } & $\begin{array}{l}\text { Grau de urbanização } \\
\text { Perfil da mão de obra (capacitação, salários } \\
\text { médios, mercado de trabalho, perspectivas de } \\
\text { evolução de emprego }\end{array}$ \\
& $\begin{array}{c}\text { Acesso a infraestrutura econômica } \\
\text { Consumo domiciliar de energia }\end{array}$ \\
\hline Informação e Conhecimento & $\begin{array}{l}\text { Fomento aos centros de inovação e pesquisa } \\
\text { sejam públicos e privados }\end{array}$ \\
\hline \multirow{3}{*}{ Aspectos Ambientais } & $\begin{array}{l}\text { Identificar as fragilidades e especificidades } \\
\text { ambientais em cada eixo. } \\
\end{array}$ \\
& Correlaciona a problemática ambiental aos \\
& investimentos futuros em infraestrutura. \\
\hline
\end{tabular}

Fonte: Org, França, K (2012). Consórcio Brasiliana (1998)

A partir desses critérios e da delimitação dos eixos foram desenvolvidas as estratégias de ações dos ENIDs em projetos-âncoras.

\section{Ações Estratégicas dos ENIDs}

As ações estratégicas dos eixos foram espacializadas em diversos fragmentos do território brasileiro. No portfólio do Consórcio Brasiliana, nota-se 
que foram elaborados estudos técnicos e a viabilidade de oito propostasâncoras para atração de investimentos privados associados às diretrizes do programa Brasil em Ação.

Os oitos projetos-âncoras foram: Porto de Sepetiba, Teleporto do Rio de Janeiro, Rodovia Mercosul, Vias navegáveis Tocantins-Araguaia, Gasoduto Bolívia-Brasil, via Navegável Rodovia BR 364/Madeira, Prodetur/Turismo Nordeste e o Porto de Suape. Esses projetos pilotos já possuíam significativas potencialidades econômicas globais, o que possibilitou a articulação de infraestrutura logística externa para o escoamento de produtos e serviços.

O projeto-âncora para a criação do Porto de Sepetiba-RJ ocorreu em virtude da localização estratégica para o escoamento de produtos. Nesse sentido foram realizados importantes investimentos na ampliação da malha ferroviária (Ferrovia Centro-Atlântica) e rodoviária como a BR 101, BR 116 e BR 040, que constituem significativos corredores que conectam o Porto de Sepetiba. Os investimentos no Porto de Sepetiba foram relacionados à infraestrutura e à logística, fortalecendo o Porto de Sepetiba como um dos principais portos em atratitividade empresarial e à redução de custos visando à concentração e escoamento de cargas (Hurt port), em especial produtos de mineração e siderurgia.

Outro projeto-âncora no estado do Rio de Janeiro foi a construção do Teleporto, conhecido como o Centro Empresarial Cidade Nova ${ }^{10}$ e constituído por um complexo de edifícios. Representa o mais importante centro de telecomunicações da América Latina. O Teleporto é responsável pela agilidade no fluxo de informações de transmissão de dados, troncos de trânsito, alta capacidade de transmissão de sinais digitais. Dentre os oitos projetos-âncoras, - Teleporto se destaca, pela inovação e difusão na agilidade e articulação de diversos segmentos econômicos nacionais e internacionais.

No eixo Amazônia houve uma série de projetos vinculados à integração econômica do Brasil com a América do Sul, com destaque para os investimentos no setor industrial, com a construção do Gasoduto Bolívia-Brasil, que reforçou o consumo e a produção da matriz energética brasileira. Esse

10 O projeto Teleporto trouxe importantes alterações na valorização imobiliária próximas ao empreendimento. 
empreendimento compreendeu construções e investimentos em mais de 130 municípios brasileiros. Correlacionado ao gasoduto, houve a criação e/ou a ampliação do modal rodoviário, com investimentos na recuperação da rodovia BR 364 (Brasília-Acre), um dos corredores multimodais de integração econômica.

Para Thérvy (2005), no segundo mandato de FHC houve significativos investimentos para a integração dos corredores multimodais rodoviários e hidroviários do eixo Amazônia. Em relação aos investimentos nos recortes dos eixos, nesse mesmo mandato mais de $50 \%$ dos investimentos foram destinados ao eixo Amazônia e Araguaia-Tocantins, em especial o fomento ao desenvolvimento de hidrovias para o escoamento da produção agrícola no eixo Araguaia-Tocantins.

Os critérios que delimitaram o recorte especial do eixo AraguaiaTocantins sofreram severas críticas. Steinberger (2003) destaca que os eixos Araguaia-Tocantins e o Oeste estão direcionados no sentido Norte-Sul, enquanto que a estrutura das redes produtivas relaciona-se a Leste-Oeste. Portanto a proposição do portfólio do Consórcio Brasiliana foi, em certa medida, uma ruptura com o modal anteriormente utilizado e mostrou ser inovador, dada a inserção de novos corredores de escoamento para o mercado externo.

Como pontos negativos cite-se a estrutura de investimentos do eixo Araguaia-Tocantins, configurada significativamente para o escoamento de grãos e logística, com poucos projetos para a inovação e consolidação para as atividades turísticas, embora, para o fomento à atividade turística, sejam necessários estudos de impactos ambientais, com vistas a mitigar o crescimento dos processos de degradação ambiental.

A inovação da política dos ENIDs refere-se às grandes obras de infraestrutura e logística que potencializaram o crescimento econômico e a competitividade internacional. Nesse sentido, o Estado realizou proposições e indicou novos caminhos para uma integração econômica, que foi ao mesmo tempo desintegradora em relação aos aspectos sociais e no enfrentamento das desigualdades regionais que marcam o território brasileiro. 
Nos aspectos de financiamento, a iniciativa privada se caracterizou como uma das principais fontes de investimentos dos ENIDs. Por isso, a proposição no portfólio dos projetos-âncoras e a ação pontual no território brasileiro na consolidação de corredores potencialmente articulados já se constituíam em importantes "mercadorias"para serem financiados.

O setor privado foi, portanto, o grande agente potencializador dos ENIDs. Já o setor público delegaria menos investimento nos projetos. Segundo Ascerald (2001), trata-se de um project finance, isto é, um instrumento financeiro que prevê a repartição dos riscos neles contidos.

Os ENIDs foram caracterizados como um projeto com fortes premissas neoliberais e cuja participação de custos-benefícios com o setor privado foi pontual e fragmentado, haja vista que os investimentos privados foram feitos em locais potencialmente estruturados ou promissores para a competitividade global.

\section{Caracterização geral do programa - Política Nacional de Desenvolvimento Regional - A PNDR}

As diretrizes do projeto de discussão da PNDR foram estabelecidas em um contexto político marcado por significativas transformações das estruturas governamentais e rumos políticos que marcou a ascensão do governo de Luis Inácio Lula da Silva (2004-2010) Trata-se de diretrizes voltadas para o enfrentamento da desigualdade regional, apresentadas no ano de 2003, incorporadas nos Planos Plurianuais e instituídas como política regional pelo Decreto 6.047/2007.

As diretrizes da PNDR diferem significativamente das diretrizes dos ENIDs, por expressar nos objetivos o fomento a programas em recortes espaciais, em certa medida não atrativos para investimentos privados, propondo modificações no modo de vida dos habitantes presentes nesses espaços e também levando em consideração a diversidade econômica, política, social e cultural, fomentando os processos endógenos.

As análises da PNDR permitem identificar dois momentos. O primeiro foi estruturado a partir das premissas da criação da PNDR no ano de 2003 e sua 
aprovação em 2007. O segundo momento refere-se aos cenários futuros da PNDR pós-2010, em especial o período de 2011-2015, dados os novos mecanismos de fundos de financiamento e as novas perspectivas do Ministério da Integração para gerir a política.

Para Bacelar (2000), a PNDR não se relaciona com políticas localistas, como, por exemplo, o combate à escassez da água na região do Nordeste. Para ela, a proposição de uma política regional precisa estar articulada à problemática nacional, envolvendo diferentes fragmentos do território brasileiro. Assim, as premissas da PNDR ${ }^{11}$ foram estabelecidas com base em três diretrizes gerais:

- Promoção e integração/articulação das instituições de governo para o esforço de redução das desigualdades regionais;

- Adoção de estratégias de ação em múltiplas escalas geográficas (em contraposição ao modelo tradicional de olhar para as macrorregiões do país, sobretudo Norte, Nordeste e Centro-Oeste);

- Consolidação da PNDR como política de Estado (e não apenas de governo, o que não garante sustentabilidade ao processo).

Essas premissas foram aprofundadas com as propostas de reativação das superintendências de desenvolvimento regional e de suas novas atribuições como articuladoras da PNDR. Nesse sentido, a escolha da escala de atuação da PNDR levou em consideração as análises espaciais com base no censo demográfico elaborados pelo FIBGE, como, por exemplos, densidade, grau de urbanização, renda per capita, níveis de empregabilidade e pesquisas do IPEA com base nas microrregiões geográficas do IBGE.

\section{Metodologia da PNDR}

Os critérios metodológicos para a tipologia de municípios prioritários para a intervenção da PNDR foram construídos pela seleção de indicadores, pela correlação desses indicadores com o tratamento espacial estatístico e a geração dos cartogramas.

\footnotetext{
${ }^{11}$ As premissas foram consultadas no documento PNDR 2010.
} 
É importante ressaltar que existem diferenças na proposta da PNDR de 2003 e as adequações da proposta da Nova PNDR pós-2010. Os indicadores que foram utilizados para a elaboração dos cartogramas foram mantidos. Entretanto, a base de dados desses indicadores apresentou modificações, em virtude da utilização de pesquisas mais recentes para a tipologia de municípios para a Nova PNDR.

\section{Quadro 05: Indicadores estruturantes da tipologia metodológica da PNDR}

\begin{tabular}{|c|c|c|}
\hline Indicadores & Matriz metodológica & Observações \\
\hline População dos Municípios & IBGE & $\begin{array}{l}\text { Censos } \\
\text { Demográficos de } \\
1991 \text { e de } 2000 \text { e } \\
\text { estimativas p/ anos } \\
\text { intercensitários }\end{array}$ \\
\hline PIB por UF & IBGE & $\begin{array}{l}\mathrm{R} \$ \text { correntes, a } \\
\text { preços de mercado, } \\
\text { anual, } \\
\text { obtidos no Ipeadata }\end{array}$ \\
\hline $\begin{array}{l}\text { PIB } \\
\text { (Agropecuária, } \\
\text { Indústria, Comércio e } \\
\text { Serviços) } \\
\text { por UF }\end{array}$ & IBGE & $\begin{array}{l}\mathrm{R} \$ \text { constantes de } \\
2000 \text {, deflacionados } \\
\text { pelo } \\
\text { deflator implícito PIB } \\
\text { Brasil, anual, } \\
\text { lpeadata. }\end{array}$ \\
\hline $\begin{array}{ll}\text { Deflatores } & \text { Setoriais } \\
\text { Implícitos } & \\
\text { do PIB por UF } & \end{array}$ & IBGE & $\begin{array}{l}\text { Dados do Sistema de } \\
\text { Contas Nacionais e } \\
\text { Regionais do IBGE }\end{array}$ \\
\hline $\begin{array}{lll}\begin{array}{l}\text { Estimativa } \\
\text { Municipais }\end{array} & & \\
\end{array}$ & $\begin{array}{c}\text { IPEA (Vergolino et } \\
\text { alli) }\end{array}$ & US\$, 1990 e 1993. \\
\hline PIB Municipais & IBGE & $\begin{array}{l}\mathrm{R} \$ \text { correntes, } 1999 \text { a } \\
2002 .\end{array}$ \\
\hline $\begin{array}{l}\text { Cesta Básica de } 16 \\
\text { Capitais }\end{array}$ & DIEESE & $\begin{array}{l}\text { média mensal, } \\
\text { preços corrente, ano } \\
\text { de 2000. }\end{array}$ \\
\hline
\end{tabular}

Fonte: PNDR 2010

Esses indicadores possibilitaram a criação de dois índices que nortearam a tipologia dos espaços sub-regionais da PNDR.

O primeiro índice foi a renda domiciliar monetária mensal per capita, estabelecida a partir das análises da pesquisa do Atlas do Desenvolvimento Humano realizada pelo IPEA, Fundação João Pinheiro e do Programa das Nações Unidas para o Desenvolvimento (PNUD), tendo como parâmetro a 
base de dados do censo 2000. Para a obtenção do índice da RDMM foi necessário correlacionar o conjunto de variáveis dos rendimentos domiciliares monetários mensais declarados pelos entrevistados e percebidos pelas famílias, englobando todas as fontes encontradas (salários, benefícios, pensões entre outros) independente de sua formalidade.

O segundo índice foi a Taxa de Variação Geométrica dos PIBs per capita. A construção desse índice foi baseada na estimativa do PIB municipal. No período de1990 a 1993 e de 1999 a 2002, as estimativas do PIB municipal foram obtidas pelo IPEA e IBGE. A atualização do PIB municipal é atualizada anualmente pelo IBGE.

Tendo como referência a elaboração desses dois índices e dos ajustes necessários, foi desenvolvido o tratamento espacial estatístico, que dividiu as microrregiões em sextis.

Figura 09: Tipologia em Sextis para a PNDR

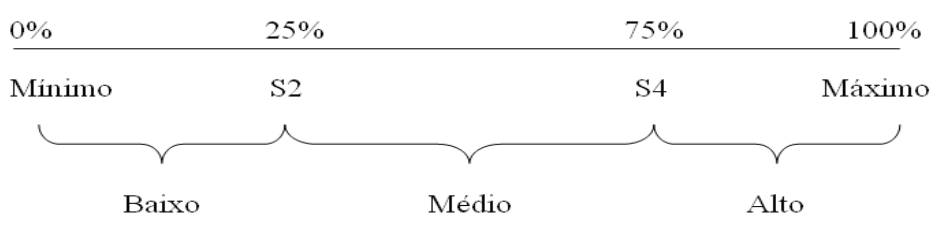

Fonte: PNDR 2010

Com essa metodologia foram elaborados cartogramas nacionais, que auxiliaram na configuração dos espaços emergenciais para a intervenção da PNDR. É importante ressaltar que a atuação da PNDR foi estruturada a partir da tipologia metodológica baseada nos recortes sub-regionais e de algumas mesorregiões diferenciadas, ou seja, em espaços com fortes desigualdades regionais que possuem conexões para além dos limites administrativos das mesorregiões delimitadas pelo IBGE. Por isso, na PNDR foi utilizada a denominação mesorregiões diferenciadas e outros recortes para espacializar as áreas prioritárias que não são exatamente as mesorregiões do IBGE. 
Figura 10:Áreas Prioritárias da PNDR

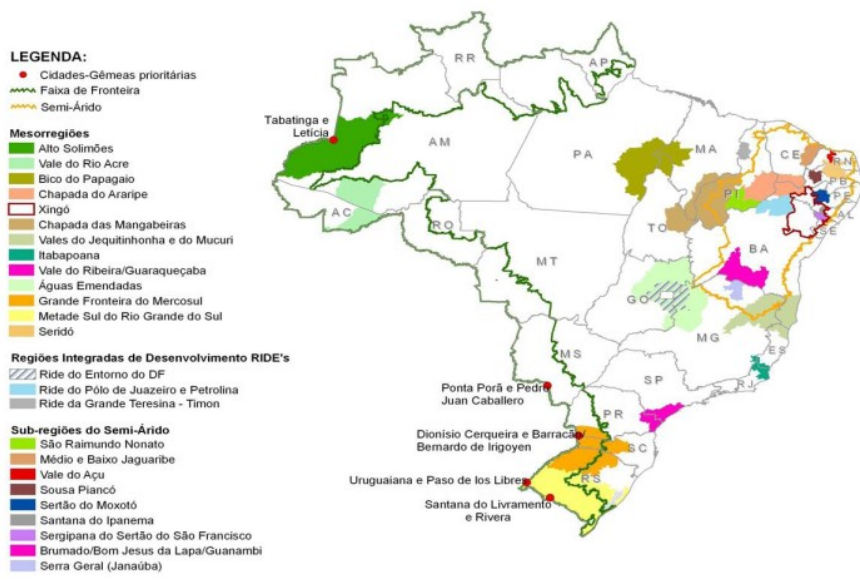

Fonte: PNDR 2010

Os índices e a definição das áreas prioritárias de intervenção da PNDR permitiram a espacialização nacional dos espaços dinâmicos, estagnados e de baixa renda para a intervenção da PNDR.

A metodologia que integra a PNDR apresenta-se mais sistematizada em relação aos critérios de delimitação desses espaços e ao tratamento espacial, permitindo identificar os espaços fortemente desiguais, no sentido de procurar a adequação da fluidez que permeia as relações intra e inter-regionais. Portanto, existe uma readequação na metodologia em relação às mesorregiões. Embora a PNDR utilize o recorte do IBGE, esse é readequado em virtude dos critérios de delimitação estadual e municipal que marcam essas mesorregiões. A partir da PNDR e das tipologias regionais, os estados inclusos nas ações prioritárias da PNDR (Fig. 11) elaboraram os planos de ação subregional, em parceria com os agentes potencializadores nesses espaços. Como exemplo dessas ações na escala sub-regional dos estados e suas parcerias destacam-se as ações de Águas Emendadas, do DF.

\section{Estratégias de Ação PNDR ${ }^{12}$}

As estratégias da PNDR obtiveram avanços em mitigar as desigualdades regionais articuladas a importantes políticas sociais voltadas para a redução das desigualdades sociais.

${ }^{12}$ As informações referentes às quatro categorias foram extraídas da PNDR 2010. 
Nesse sentido, os avanços da PNDR, em sua segunda fase, referem-se ao principal desafio de se distanciar das políticas regionais de governo para uma política de Estado. Portanto, nas diretrizes da PNDR há uma explicitação em relação à preocupação da PNDR de não apenas ser compreendida como uma política de governo ou segmentos de governo, mas de buscar articulações interministeriais para a sua consolidação como política de Estado.

Do aporte metodológico foi possível espacializar quatro categorias de unidades regionais:

1 - Territórios com padrão consolidado de competitividade, em que se encontram as MRGs de alta renda espacializadas na região Sul, Sudeste, partes da fronteira agrícola e nas maiores concentrações urbanas das regiões Norte e Nordeste;

2 - Territórios em processo de incorporação econômica à dinâmica nacional são espaços que recentemente integraram a estrutura produtiva econômica brasileira, em especial partes da região Centro-Oeste e Nordeste. Esses espaços ainda possuem pouca representatividade no PIB nacional;

3 - Territórios com padrão prolongado de estagnação - são espaços que possuem uma estagnação econômica resultante das crises econômicas e reduzidos investimentos na atualidade. Esses espaços anteriormente representavam um dinamismo econômico. A espacialização desse recorte não se apresenta muito claro na PNDR, podendo ocorrer em todas as regiões brasileiras. Esses espaços representam 18\% da representatividade no PIB nacional;

4 - Territórios com fragilidade econômica - são espaços excluídos dos investimentos econômicos e, portanto prioritários para as estratégias de fomento ao desenvolvimento e enfrentamento das desigualdades regionais pela PNDR. Nesses espaços a PNDR desenvolveu importantes princípios para o fomento ao desenvolvimento, quais sejam, participação social e empoderamento; criação e fomento de governança de importantes agentes nesses espaços; efetividade das estratégias de enfrentamento levando em consideração a escala cotidiana, isto é, o lugar. 
São esses os princípios e desafios para o enfrentamento da questão regional explicitados na atuação da PNDR para 2011-2015, articulada com importantes políticas sociais, como a Política Bolsa Família, que atende significativamente territórios que integram o grupo 4 da PNDR.

As estratégias da PNDR não se resumem à atuação no grupo 4. Há diferentes formas de enfrentamento e estratégias para os demais grupos. No entanto, é no grupo 4 que se observa a prioridade das ações e investimentos. Dentre os desafios de uma política de desenvolvimento regional, um deles diz respeito ao fortalecimento de fundos de investimentos para a efetividade das ações de enfrentamento, com a aprovação do Fundo Nacional de Desenvolvimento Regional.

Existem avanços com a PNDR para as ações de enfrentamento regional, como o fomento a uma política que de fato atue e modifique socioeconomicamente os espaços precarizados, reduzindo, portanto, as desigualdades regionais. Em contrapartida, existem fragilidades das diversas esferas federativas para a consolidação do Fundo Nacional de Desenvolvimento Regional e os mecanismos de coordenação para ações do enfrentamento a desigualdade regional bem como as ações delineadas no plano de ações dos estados.

\section{Apontamentos finais}

As análises desenvolvidas neste artigo procuram apontar as diferentes regionalizações brasileiras articuladas às tipologias metodológicas, assim como as novas inserções teóricas que marcaram o percurso das diferentes regionalizações empreendidas no território brasileiro, diante da necessidade de repensar a regionalização oficial, em virtude dos novos agentes que produzem o território brasileiro no século XXI.

Nesse sentido, as pesquisas divulgadas pela FIBGE se constituem em importantes fontes de análises metodológicas, para espacializar a dinâmica urbano-regional brasileira com critérios técnicos e análise de fonte de dados que possibilitam a compreensão das hierarquias urbano-regionais. As fontes de dados disponibilizadas pelo IBGE se constituem em importantes critérios para a 
delimitação, espacialização e eficiência de ações das políticas públicas. O IBGE, em várias políticas públicas, realizou parcerias para a construção de diferentes recortes regionais, que melhor atendam às diretrizes das políticas públicas.

A partir da historiografia das regionalizações procurou-se aprofundar a relação dos diferentes recortes regionais empreendidos nas políticas públicas ou programas de fomento ao desenvolvimento. Embora essa análise seja parcial, o olhar empreendido dessas distintas regionalizações e critérios das políticas e programas foi centralizado no fomento ao desenvolvimento regional, com distintos posicionamentos políticos e metodológicos que marcaram as duas políticas. Há necessidade de ampliação das análises com outras políticas públicas, como, por exemplos, a regionalização do Sistema Único de Saúde, o programa Luz para Todos, as ações do Programa de Aceleração e do Crescimento (PAC) para as regiões metropolitanas, entre outros.

O pressuposto das análises das duas políticas em tempos e espaços distintos não é o de afirmação de que a PNDR melhor representa uma política regional que os ENIDs. Existem importantes pesquisas que abordam a distinção e as fragilidades dos ENIDs e do PNDR, como referenciado em alguns momentos neste artigo.

A perspectiva foi de buscar uma análise baseada na estrutura metodológica dessas políticas, o que permitiu compreender os distintos recortes espaciais para a sua atuação. As ações dos ENIDs, voltadas para a integração econômica de espaços já potencialmente articulados, diante da reduzida aplicação dos critérios metodológicos que nortearam a seleção dos projetos-âncoras, revelaram a existência de um descompasso e de fragilidade metodológica entre a técnica e os espaços de ação. As ações da PNDR, com foco na atuação de espaços fragilizados socialmente, apresentam uma metodologia mais consolidada, em termos de critérios e delimitação dos recortes regionais.

Ambas as políticas atuam, em certa medida, com ações de fomento que potencializam o fortalecimento de agentes privados já conectados espacialmente em determinados fragmentos do território brasileiro. No entanto, 
a política dos ENIDs propicia significativos investimentos em espaços potencializados, que vieram a ser fortalecidos pela PNDR para a integração produtiva brasileira, em especial nas ações esboçadas nos PPAs dos estados.

As análises parcialmente empreendidas possibilitaram a elaboração de alguns questionamentos para futuras análises, como contribuição para a ciência geográfica em resgatar e inovar análises na perspectiva regional diante do processo de revisão da PNDIR explicitado na Carta Nacional para o Desenvolvimento Regional, que incorpora as diretrizes elegidas na I Conferência do Desenvolvimento Regional realizada no mês de março de 2013.

Para tanto, é necessário aprofundar o debate acerca dos critérios empreendidos nas ações regionalizadores, correlacionados com a prática. Para isso, questões como as que seguem são pertinentes: 1) Como buscar a intersetorialidade de diversas políticas se elas partem de distintos recortes regionais e metodologias? 2) É possível adotar uma única regionalização para o fomento a políticas sociais? 3) Quais seriam os critérios? 4) Como a geografia pode contribuir nessas análises para fortalecer a concertação entre as políticas públicas?

Os questionamentos não têm como objetivo encontrar respostas intempestivamente. Pelo contrário, possuem a premissa da reflexão metodológica apontando a viabilidade, fragilidade e avanços das diferentes tipologias e sua relação com a ação das políticas. Dispõe-se de importantes estudos que analisam distintas políticas, ainda que eles reconheçam a regionalização de forma a priori dessas políticas sem realizar a correlação com os aspectos metodológicos expressos nas políticas, no sentido de questionarem metodologicamente o recorte e propor modificações que melhor atendam às necessidades e eficiência das políticas no território. 


\section{Bibliografia}

ABLAS, L. Estudo dos Eixos como instrumento de planejamento regional.In: GONÇALVES, M.F; BRANDAO, C; GALVAO, A.C.F. Regiões e cidades, cidades nas regiões: o desafio urbano-regional, São Paulo, UNESP-ANPUR, 2003.

ACSELRAD, Henri. Eixos de Articulação Territorial e Sustentabilidade do Desenvolvimento no Brasil.- Rio de Janeiro: Projeto Brasil Sustentável e Democrático: Fase, 2001. 103 p. (Série Cadernos Temáticos, n. 10)

BACELAR, T. Ensaios sobre o desenvolvimento brasileiro: heranças e urgências. Rio de Janeiro,Revan: Fase,2000.

BECKER, B. K. . Crescimento Econômico e Estrutura Espacial do Brasil. Revista Brasileira de Geografia. Rio de Janeiro, v. 34, n.4, p. 73-109, 1972.

BEZZI, Meri Lourdes. Região: uma (re) visão historiográfica da gênese aos novos paradigmas. Santa Maria: UFSM, 2004. 292 p.

BORGES, Loçandra. Mapas produzidos para aulas da disciplina didática e prática de ensino de geografia, Geografia, UFG, 2002. Disponível em:

www.iesa.ufg.br

CANO, W. Desequilíbrios Regionais e Concentração Industrial no Brasil: 1930-1995. 2. ed. Campinas: Instituto de Economia da Universidade Estadual de Campinas, 1998.

CONSÓRCIO BRASILIANA,. (Booz Allen, Bechtek \& ABN Amro) Relatório preliminar do marco inicial do serviço e visão estratégica 2020. Brasília BNDES e Ministério de Orçamento e Gestão, 1998.

CORREA, Roberto Lobato. Região e Organização espacial. São Paulo: Ática, 1987.

EGLER, C. Eixos Nacionais de Integração de Desenvolvimento: impactos ambientais prováveis 2001. Disponível em: www.egler.com.br

FAISSOL, S/. Regiões Nodais/funcionais: Alguns comentarios conceituais e metodológicos. In: RBG, ano 37 n, 01, 1975.

GALVAO,C.F; BRANDAO, C.A. Fundamentos, motivações e limitações da proposta dos "Eixos Nacionais de Integração e Desenvolvimento.In: GONÇALVES, M.F; BRANDAO, C; GALVAO, A.C.F. Regiões e cidades, cidades nas regiões: o desafio urbano-regional, São Paulo, UNESP-ANPUR, 2003

GEIGER, Pedro Pinchas. Regionalização.Revista Brasileira de Geografia. Rio de Janeiro, v. 31, n 1, Jan/Mar, 1969.

HAESBAERT, R. . Regional-Global: dilemas da região e da regionalização na Geografia contemporânea. 1. ed. Rio de Janeiro: Bertrand Brasil, 2010. 
IBGE/ REGIC, Regiões de Influências das cidades. 2007, Rio de Janeiro, 2008.

IBGE, Projeto de divisão regional do Brasil em mesorregiões e microrregiões geográficas., 2008a.

LIMONAD, Ester. Brasil século XXI - Regionalizar para que? Para quem? In: LIMONAD, Ester, HAESBAERT, R. \& MOREIRA, R. (Org.). Brasil século XXI - por uma nova regionalização? Agentes, processos e escalas. São Paulo: Max Limonad, 2004.

MAGNAGO, A.A. A Divisão Regional Brasileira - uma revisão bibliográfica. In: RBG Rio de Janeiro,vol 57,n 04, p. 67-94, 1995.

MOREIRA, R. . O Pensamento Geográfico Brasileiro. São Paulo: Contexto, 2008. v. 1. 190 p.

MINISTERIO DA INTEGRACÃO NACIONAL-SECRETARIA DE POLÍTICAS DE DESENVOLVIMENTO REGIONAL. A PNDR em dois tempos: A experiência apreendida e o olhar pós 2010.Brasília, 2010.

SANTOS, Milton. Por uma Geografia nova. São Paulo: Hucitec-Edusp, 1978

SANTOS, M.; SILVEIRA, M. L. O Brasil: território e sociedade no início do século XXI. Rio de Janeiro: Record, 2001

SILVA NETO, Manoel Lemes. A Questão Regional Hoje: Reflexões a Partir do Caso Paulista. In: SOUZA, Maria Adélia Aparecida de. Território Brasileiro: Usos e abusos. Campinas-SP. Ed. Territorial, 2003.

STEINBERGER, M O significado da Região Centro Oeste na espacialidade do desenvolvimento brasileiro: uma análise geopolítica..In: GONÇALVES, M.F; BRANDAO, C; GALVAO, A.C.F. Regiões e cidades, cidades nas regiões: 0 desafio urbano-regional, São Paulo, UNESP-ANPUR, 2003.

THÉRY, Hervé. Situações da Amazônia no Brasil e no continente. In: Estud. av. vol.19 no.53 São Paulo Jan./Apr. 2005. 